\title{
Dielectric Properties of Ni-Zn Ferrites Synthesized by Citrate Gel Method
}

\author{
K. Rama Krishna ${ }^{1}$, Dachepalli Ravinder ${ }^{2 *}$, K. Vijaya Kumar ${ }^{3}$, Utpal S. Joshi ${ }^{4}$, V. A. Rana ${ }^{4}$, \\ Abrham Lincon ${ }^{5}$ \\ ${ }^{1}$ Department of Physics, Malla Reddy College of Engineering \& Technology, Secunderabad, India; ${ }^{2}$ Department of Physics, P.G. \\ College of Science, Osmania University, Hyderabad, India; ${ }^{3}$ Department of Physics, Jawaharlal Nehru Technological University, \\ Hyderabad, India; ${ }^{4}$ Department of Physics, Gujarat University, Ahmedabad, India; ${ }^{5}$ Department of Chemsitrys, P.G. College of \\ Science, Osmania University, Hyderabad, India. \\ Email: *ravindergupta28@rediffmail.com
}

Received June 30 ${ }^{\text {th }}, 2011$; revised July $28^{\text {th }}, 2011$; accepted August $10^{\text {th }}, 2011$

\begin{abstract}
Ni-Zn ferrite with composition of $\mathrm{Ni}_{1-x} \mathrm{Zn}_{x} \mathrm{Fe}_{2} \mathrm{O}_{4}(x=0.0,0.2,0.4,0.6,0.8,0.9,1.0)$ were prepared by citrate gel method. The Dielectric Properties for all the samples were investigated at room temperature as a function of frequency. The dielectric constant shows dispersion in the lower frequency region and remains almost constant at higher frequencies. The frequency dependence of dielectric loss tangent $(\tan \delta)$ is found to be abnormal, giving a peak at certain frequency for mixed Ni-Zn ferrites. A qualitative explanation is given for the composition and frequency dependence of the dielectric loss tangent.
\end{abstract}

Keywords: Ferrites; Citrate Method; Lattice Parameter; Dielectric Constant; Dielectric Loss

\section{Introduction}

$\mathrm{Ni}$-Zn ferrite is a well-known spinel magnetic material. In the inverse spinel structure of $\mathrm{NiFe}_{2} \mathrm{O}_{4}$, the tetrahedral sites are occupied by ferric ions and octahedral sites by ferric and nickel ions. $\mathrm{Ni}_{1-x} \mathrm{Zn}_{x} \mathrm{Fe}_{2} \mathrm{O}_{4}$ ferrites are ferrimagnetic materials with a large number of technological applications in telecommunications and entertainment electronics. Ni-Zn ferrites are among the most widely used soft magnetic materials because of high frequency applications as they posses high electrical resistivity and low eddy current losses [1-3]. It is known that magnetic properties of ferrites are sensitive to preparation technique and their microstructures [4]. The electrical and magnetic properties of such ferrites depend strongly on distribution of cations at the tetrahedral (A) and octahedral (B) sites in the lattice [5-7]. It is well known that zinc ions can be used to alter the saturation magnetization. It is believed that the addition of zinc ions also affects the lattice parameter and it would therefore be expected to change the Curie temperature of the material [8]. The substitution of divalent ions in pure ferrites leads to the modification of the structural, electrical and magnetic properties [9]. The conventional solid-state reaction route is widely used for the production of ferrite because of its low cost and suitability for large scale production.

\footnotetext{
"Corresponding author.
}

The citrate method is used to speed up the synthesis of complex materials. It is a simple process, which offers a significant saving in time and energy consumption over the traditional methods. Several researchers have reported the synthesis of Ni-Zn ferrites using different techniques like, refluxing process [10], ceramic [11], hydrothermal [12], combustion [13], co-precipitation [14], reverse micelle process [15], spark plasma sintering [16], micro emulsion [17] and ball milling etc.

In this work, we present the results of systematic doping of non-magnetic Zn content on the dielectric properties of Ni-Zn ferrite synthesized by citrate method.

\section{Experimental}

The starting materials were nickel nitrate, zinc nitrate, iron nitrate, citric acid and ammonia all of analytical grade. The solution of nickel nitrate $\left(\mathrm{Ni}\left(\mathrm{NO}_{3}\right)_{2} \cdot 6 \mathrm{H}_{2} \mathrm{O}\right.$, ferric nitrate $\left(\mathrm{Fe}\left(\mathrm{NO}_{3}\right)_{3} \cdot 9 \mathrm{H}_{2} \mathrm{O}\right)$ and zinc nitrate $\left(\mathrm{Zn}\left(\mathrm{NO}_{3}\right)_{2} \cdot 6 \mathrm{H}_{2} \mathrm{O}\right)$ in their stoichiometry were dissolved in a de ionized water. Citric acid was then added to the prepared aqueous solution to chelate $\mathrm{Ni}^{2+}, \mathrm{Zn}^{2+}$ and $\mathrm{Fe}^{3+}$ in the solution. The molar ratio of citric acid to total moles of nitrate ions was adjusted at 1:3. The mixed solution was neutralized to $\mathrm{pH} 7$ by adding ammonia $\left(\mathrm{NH}_{3}\right)$ solution. The neutralized solution was evaporated to dry ness by heating at $100^{\circ} \mathrm{C}$ on a hot plate with continuous stirring, until it becomes 
viscous and finally formed a very viscous gel. Increasing the temperature up to $200^{\circ} \mathrm{C}$ leads to ignition of gel. The dried gel burnt completely in a self propagating combustion manner to form a loose powder. Finally the burnt powder was calcined in air at temperature of $1000^{\circ} \mathrm{C}$ for one hour to obtain spinel phase. Afterwards the powder was pressed into pellets of thickness $3 \mathrm{~mm}$ and a diameter of $10 \mathrm{~mm}$ with press by applying a pressure of 2 tons/in ${ }^{2}$. The final sintering was done at $1000^{\circ} \mathrm{C}$, afterwards the pellets were coated with silver paint for better electrical contact to measure the dielectric properties.

The structural characterizations of all samples were carried out by X-ray diffraction (XRD) and conforms the well defined single phase spinel structure. XRD data were taken at room temperature using $\mathrm{CuK} \alpha$ radiation. The dielectric data are measured by LCR meter at room temperature in the frequency range $2 \mathrm{~Hz}$ to $2 \mathrm{MHz}$.

\section{Results and Discussions}

All the zinc substitute nickel ferrites of the various compositions show the crystalline cubic spinel structure. The sharp peaks showed all-crystalline nature of single phase ferrite. The lattice parameter of individual composition was calculated by using the formula

$$
a=d\left(h^{2}+k^{2}+1^{2}\right)^{1 / 2}
$$

where, $a=$ lattice constant;

$d=$ inter planar distance;

$(h, k, \mathrm{l})=$ the Miller indices.

The variation of lattice parameter with zinc composition is shown in Figure 1. The lattice parameter is found vary linearly with increasing zinc concentration, there by indicating that the Ni-Zn ferrite system obeys Vegard's law [18]. A similar behavior of lattice constant with dopant concentration was observed by several investigators in various ferrite systems [19-21]. The variation in lattice constant with zinc content can be explained on the basis of the ionic radii of $\mathrm{Zn}^{2+}(0.82 \AA)$ ions is higher than that of $\mathrm{Ni}^{2+}(0.78 \AA)$ [22].

\subsection{Dielecric Constant with Frequency}

The effect of frequency on the real dielectric constant $\left(\varepsilon^{\prime}\right)$ can be seen from Figure 2 and that the value of dielectric constant decreases continuously with increasing frequency. The decrease in the values of dielectric constant as the frequency increases can be due to electron exchange interaction between $\mathrm{Fe}^{2+}$ and $\mathrm{Fe}^{3+}$ ions, which cannot follow the alternating electric field. The decrease of dielectric constant with increase of frequency as observed in the case of Ni-Zn ferrite. A similar behavior was also observed in [23-26] of various ferrite systems. The explanation for the decrease in the values of $\varepsilon^{\prime}$ as the frequency increases can be related to electron exchange interaction between $\mathrm{Fe}^{2+}$ and $\mathrm{Fe}^{3+}$ ions which cannot follow the alternation of the electric field beyond a certain frequency.

\subsection{Dielectric Loss Tangent $(\tan \delta)$ with Frequency}

The variation of $\tan \delta$ with frequency can be seen from Figure 3, it can be seen from the figure that in the case of $\mathrm{NiFe}_{2} \mathrm{O}_{4}, \mathrm{Ni}_{0.8} \mathrm{Zn}_{0.2} \mathrm{Fe}_{2} \mathrm{O}_{4}, \mathrm{Ni}_{0.6} \mathrm{Zn}_{0.4} \mathrm{Fe}_{2} \mathrm{O}_{4}$ and

$\mathrm{Ni}_{0.4} \mathrm{Zn}_{0.6} \mathrm{Fe}_{2} \mathrm{O}_{4} \tan \delta$ shows maximum at a frequency of $21 \mathrm{~Hz}$, in the case of $\mathrm{Ni}_{0.1} \mathrm{Zn}_{0.9} \mathrm{Fe}_{2} \mathrm{O}_{4}, \mathrm{ZnFe}_{2} \mathrm{O}_{4} \tan \delta$ shows maximum at a frequency of $22 \mathrm{~Hz}$ and $\mathrm{Ni}_{0.2} \mathrm{Zn}_{0.8} \mathrm{Fe}_{2} \mathrm{O}_{4}$ $\tan \delta$ shows maximum at $25 \mathrm{~Hz}$. A qualitative explanation can be given for the occurrence of the maxima in $\tan \delta$ verses frequency curves in $\mathrm{NiFe}_{2} \mathrm{O}_{4}, \mathrm{Ni}_{0.8} \mathrm{Zn}_{0.2} \mathrm{Fe}_{2} \mathrm{O}_{4}$, $\mathrm{Ni}_{0.6} \mathrm{Zn}_{0.4} \mathrm{Fe}_{2} \mathrm{O}_{4}, \mathrm{Ni}_{0.4} \mathrm{Zn}_{0.6} \mathrm{Fe}_{2} \mathrm{O}_{4}, \mathrm{Ni}_{0.1} \mathrm{Zn}_{0.9} \mathrm{Fe}_{2} \mathrm{O}_{4}, \mathrm{ZnFe}_{2} \mathrm{O}_{4}$ and $\mathrm{Ni}_{02} \mathrm{Zn}_{0.8} \mathrm{Fe}_{2} \mathrm{O}_{4}$, as pointed out by Iwauchi [27], there is a strong correlation between the conduction mechanism and the dielectric behavior of ferrites. The conduction mechanism in $n$-type ferrites is considered as due

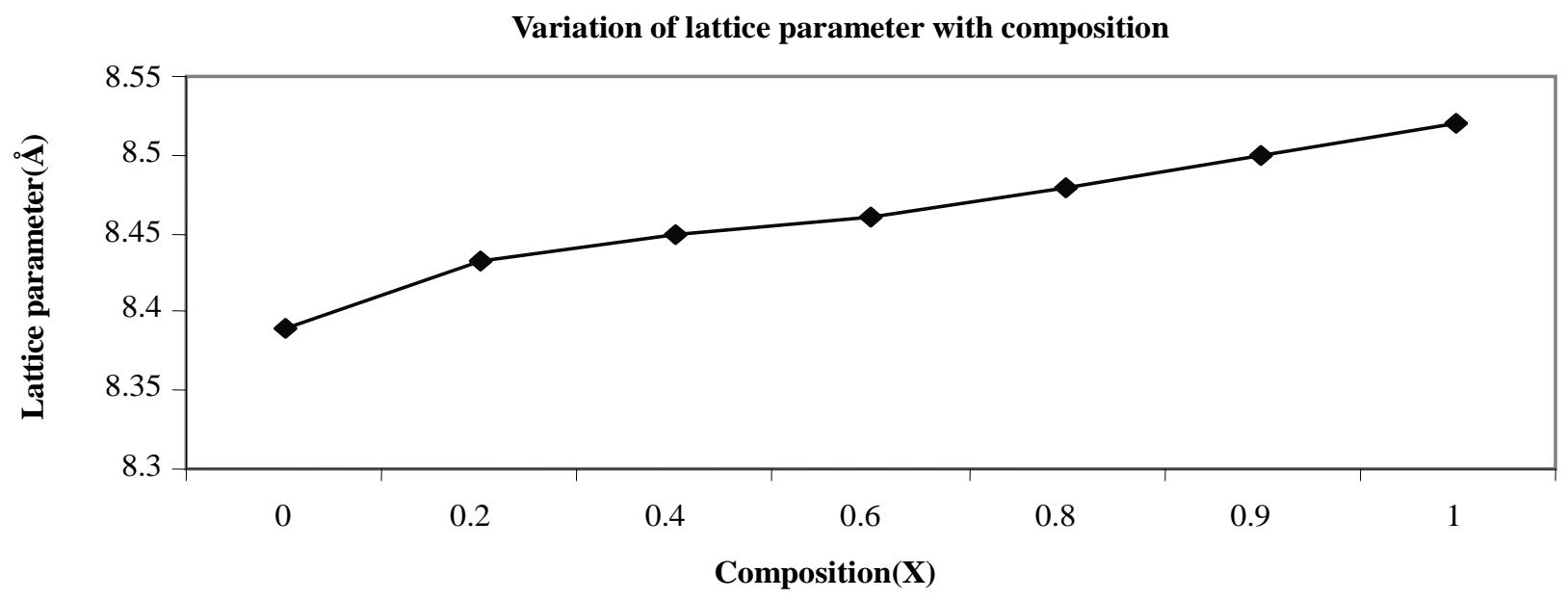

Figure 1. Variation of lattice parameter with composition. 


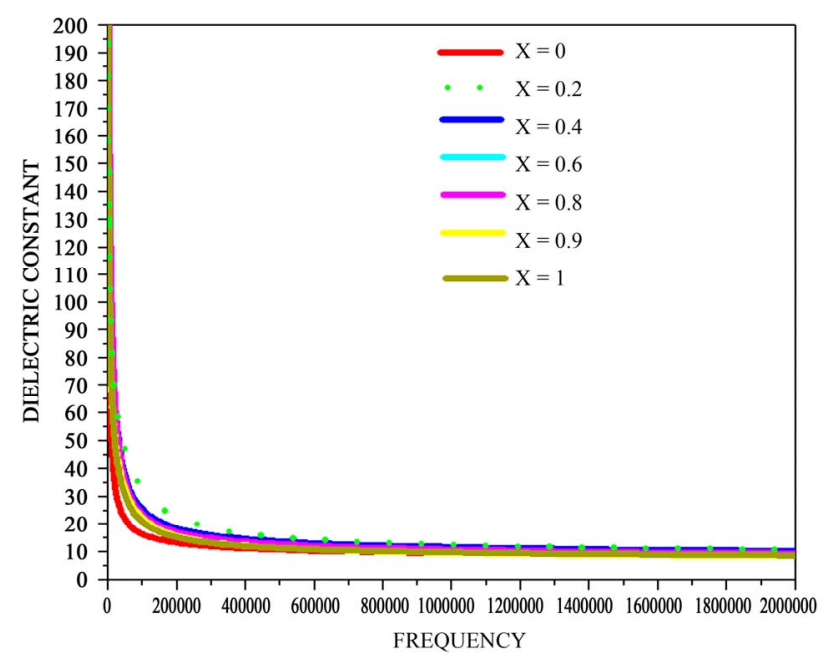

Figure 2. Variation of dielectric constant with composition.

to hopping of electrons between $\mathrm{Fe}^{2+}$ and $\mathrm{Fe}^{3+}$ situated on the octahedral sites. As seen, when the hopping frequency is nearly equal to that of external applied electric field a maximum of loss tangent may be observed [28]. As such it is possible that in the case of in $\mathrm{NiFe}_{2} \mathrm{O}_{4}, \mathrm{Ni}_{0.8} \mathrm{Zn}_{0.2} \mathrm{Fe}_{2} \mathrm{O}_{4}$, $\mathrm{Ni}_{0.6} \mathrm{Zn}_{0.4} \mathrm{Fe}_{2} \mathrm{O}_{4}, \mathrm{Ni}_{0.4} \mathrm{Zn}_{0.6} \mathrm{Fe}_{2} \mathrm{O}_{4}, \mathrm{Ni}_{0.1} \mathrm{Zn}_{0.9} \mathrm{Fe}_{2} \mathrm{O}_{4}, \mathrm{ZnFe}_{2} \mathrm{O}_{4}$ and $\mathrm{Ni}_{02} \mathrm{Zn}_{0.8} \mathrm{Fe}_{2} \mathrm{O}_{4}$, the hoping frequencies are of the approximate magnitude to observe a loss maximum at 21 , 22, $25 \mathrm{~Hz}$ respectively.

\subsection{Conclusion}

It may be concluded that a series of $\mathrm{Ni}-\mathrm{Zn}$ ferrite with compositional formula $\mathrm{Ni}_{1-x} \mathrm{Zn}_{x} \mathrm{Fe}_{2} \mathrm{O}_{4}$ where $x=0.0,0.2$, $0.4,0.6,0.8,0.9 \& 1.0$ are prepared by citrate gel method. The lattice constant was found to be increases with zinc composition. The variation of dielectric constant and dielectric loss tangent was explained on the basis of electronic exchange between the $\mathrm{Fe}^{2+}$ and $\mathrm{Fe}^{3+}$ ions.

\section{Acknowledgements}

The authors are grateful Dr. Partha sarthy Principal, P.G. College of Science, Osmania University, Hyderabad for his encouragement in research work. One of the author K. Rama Krisna is grateful to V. S. K. Reddy, Principal, Malla Reddy College Of Engineering \& Technology, Hyderabad. And the other author K. Vijaya Kumar is grateful to Dr. A. Govardhan, Principal JNTUH College of Engineering, Nachupally, Karim Nagar (Dist).

\section{REFERENCES}

[1] X. He, G. Song and J. Zhu, "Non-Stoichiometric Ni-Zn Ferrite by Sol-Gel Processing," Materials Letters, Vol. 59, No. 14-15, 2005, pp. 1941-1944. doi:10.1016/j.matlet.2005.02.031

[2] Y. Matsuo, M. Inagaki, T. Tomozawa and F. Nakao,

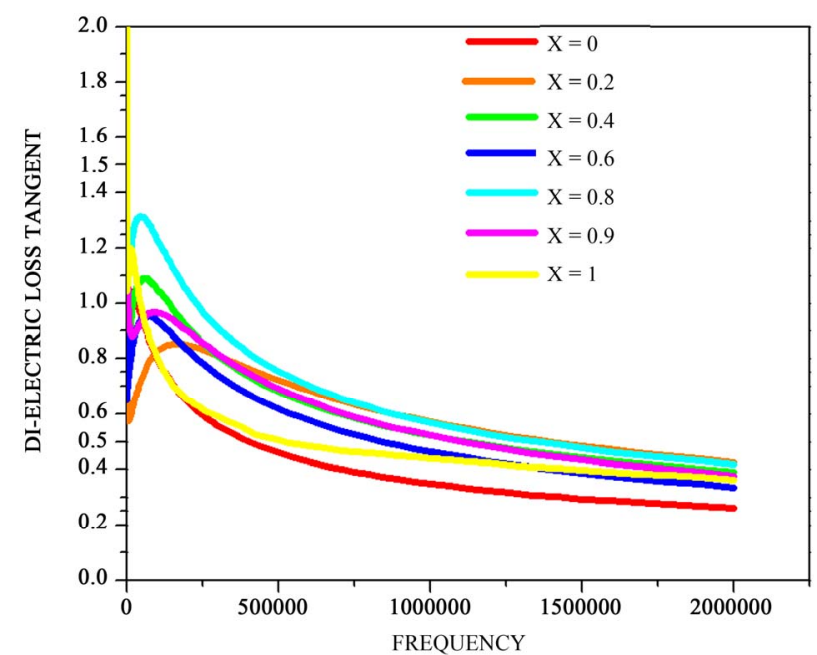

Figure 3. variation of dielectric loss tangent with composition.

“High Performance Ni-Zn Ferrite,” IEEE Transactions on Magnetics, Vol. 37, No. 4, 2001, pp. 2359-2361. doi: $10.1109 / 20.951172$

[3] P. S. A. Kumar, J. J. Shrotri, S. D. Kulkarni, C. E. Deshpande and S. K. Date, "Low Temperature Synthesis of $\mathrm{Ni}_{0.8} \mathrm{Zn}_{0.2} \mathrm{Fe}_{2} \mathrm{O}_{4}$ Powder and Its Characterization," $\mathrm{Ma}$ terials Letters, Vol. 27, No. 6, 1996, pp. 293-296. doi:10.1016/0167-577X(96)00010-9

[4] H. Su, H. Zhang, X. Tang, Y. Jing and Y. Liu, "Effects of Composition and Sintering Temperature on Properties of Ni-Zn and NiCuZn Ferrites," Journal of Magnetism and Magnetic Materials, Vol. 310, No. 1, 2007, pp. 17-21. doi:10.1016/j.jmmm.2006.07.022

[5] J. L. Dormann and M. Nogues, "Magnetic Structures in Substituted Ferrites," Journal of Physics: Condensed Matter, Vol. 2, No. 5, 1990, pp. 1223-1237. doi:10.1088/0953-8984/2/5/014

[6] N. Rezlescu, E. Rezlescu, C. Pasnicu and M. L. Craus, "Effects of the Rare-Earth Ions on Some Properties of a Nickel-Zinc Ferrite,” Journal of Physics: Condensed Matter, Vol. 6, No. 29, 1994, pp. 5707-5716. doi:10.1088/0953-8984/6/29/013

[7] A. E. Virden and K. O’Grady, "Structure and Magnetic Properties of Ni-Zn Ferrite Nanoparticles,” Journal of Magnetism and Magnetic Materials, Vol. 290-291, No. 2, 2005, pp. 868-870. doi:10.1016/j.jmmm.2004.11.398

[8] A. M. El-Sayed, "Influence of Zinc Content on Some Properties of Ni-Zn Ferrites," Ceramics International, Vol. 28, No. 4, 2002, pp. 363-367. doi:10.1016/S0272-8842(01)00103-1

[9] Z. Zhong, Q. Li, Y. Zhang, H. Zhong, M. Cheng and Y. Zhang, "Synthesis of Nanocrystalline Ni-Zn Ferrite Powders by Refluxing Method,” Powder Technology, Vol. 155, No. 3, 2005, pp. 193-195. doi:10.1016/j.powtec.2005.05.060

[10] A. Dias and R. L. Moreira, "Chemical, Mechanical and Dielectric Properties after Sintering of Hydrothermal Nickel-Zinc Ferrites,” Materials Letters, Vol. 39, No. 1, 1999, pp. 69-76. doi:10.1016/S0167-577X(98)00219-5 
[11] S. E. Jacobo, S. Duhalde and H. R. Bertorello, "Rare Earth Influence on the Structural and Magnetic Properties of NiZn Ferrites," Journal of Magnetism and Magnetic Materials, Vol. 272-276, No. 3, 2004, pp. 2253-2254. doi:10.1016/j.jmmm.2003.12.564

[12] S. D. Shenoy, P. A. Joy and M. R. Anantharaman, "Effect of Mechanical Milling on the Structural, Magnetic and Dielectric Properties of Coprecipitated Ultrafine Zinc Ferrite,” Journal of Magnetism and Magnetic Materials, Vol. 269, No. 2, 2004, pp. 217-226. doi:10.1016/S0304-8853(03)00596-1

[13] S. A. Morrison, C. L. Cahill, E. E. Carpenter, S. Calvin, R. Swaminathan, M. E. McHenry and V. G. Harris, "Magnetic and Structural Properties of Nickel Zinc Ferrite Nanoparticles Synthesized at Room Temperature,” Journal of Applied Physics, Vol. 95, No, 11, 2004, pp. 63926395. doi:10.1063/1.1715132

[14] J. Sun, J. Li, G. Sun and W. Qu, "Synthesis of Dense NiZn Ferrites by Spark PLasma Sintering," Ceramics International, Vol. 28, No. 8, 2002, pp. 855-858. doi:10.1016/S0272-8842(02)00064-0

[15] A. Verma, T. C. Goel, R. G. Mendiratta and M. I. Alam, "Dielectric Properties of NiZn Ferrites Prepared by the Citrate Precursor Method," Materials Science and Engineering: $B$, Vol. 60, No. 2, 1999, pp. 156-162. doi:10.1016/S0921-5107(99)00019-7

[16] G. P. Lopez, S. P. Silvetti, S. E. Urreta and E. D. Cabanillas, "Magnetic Interactions in High-Energy BallMilled NiZnFe $\mathrm{O}_{4} / \mathrm{SiO}_{2}$ Composites," Physica B, Vol. 398, No. 2, 2007, pp. 241-244. doi:10.1016/j.physb.2007.04.024

[17] C. Upadhyay, D. Mishra, H. C. Verma, S. Anand and R. P. Das, "Effect of Preparation Conditions on Formation of Nanophase Ni-Zn Ferrites through Hydrothermal Technique," Journal of Magnetism and Magnetic Materials, Vol. 260, No. 1-2, 2003, pp. 188-194. doi:10.1016/S0304-8853(02)01320-3

[18] L. Vegard, "The Constitution of Mixed Crystals and the Space Occupied by Atoms,” Zeitschrift für Physik, Vol. 5, No. 17,1921 , pp. 17-26.
[19] Y.-P. Fu and S.-H. Hu, "Electrical and Magnetic Properties of Magnesium-Substituted Lithium Ferrite,” Ceramics International, Vol. 36, No. 4, 2010, pp. 1311-1317.

[20] R. G. Kharake, R. S. Devan and B. K. Chougalu, "Structural and Electrical Properties of Cd-Substituted Li-Ni Ferrites," Journal of Alloys and Compounds, Vol. 463, No. 1-2, 2008, pp. 67-72.

[21] B. R. Karache, B. V. Khasbardar and A. S. Vanigam, "X-Ray, SEM and Magnetic Properties of Mg Cd Ferrites," Journal of Magnetism and Magnetic Materials, Vol. 168, No. 3, 1997, pp. 292-298. doi:10.1016/S0304-8853(96)00705-6

[22] R. D. Shanoss and C. T. Prewitt, "Revised Values of Effective Ionic Radii,” Acta Crystallographica, Vol. 1326, No. 7, 1970, pp. 1046-1048.

[23] S. Mahalakshmi and K. Srinivasa Manja, “ac Electrical Conductivity and Dielectric Behavior of Nanophase Nickel Ferrites,” Journal of Alloys and Compounds, Vol. 457, No. 1-2, 2008, pp. 522-525.

[24] D. Ravinder and P. V. B. Redddy, "High-Frequency Dielectric Behaviour of Li-Mg Ferrites,” Materials Letters, Vol. 57, No. 26-27, 2003, pp. 4344-4350. doi:10.1016/S0167-577X(03)00093-4

[25] N. Rezlescu and E. Rezlescu, "Abnormal Dielectric Behaviour of Copper Containing Ferrites,” Solid State Communications, Vol. 14, No. 1, 1974, pp. 69-72.

[26] V. R. Murthy and J. Sobbhandari, "Dielectric Properties of Some Nickel-Zinc Ferrites at Radio Frequency,” State Solid Physics A, Vol. 36, No. 2, 1976, pp. K133-K135.

[27] K. Iwauchi, "Dielectric Properties of Fine Particles of $\mathrm{Fe}_{3} \mathrm{O}_{4}$ and Some Ferrites," Japanese Journal of Applied Physics, Vol. 10, No. 11, 1971, pp. 1520-1528. doi:10.1143/JJAP.10.1520

[28] A. M. Abdeen, O. M. Hemeda, E. E. Assem and M. M. EI-sehly, "Structural, Electrical and Transport Phenomena of Co Ferrite Substituted by Cd," Journal of Magnetism and Magnetic Materials, Vol. 238, No. 1, 2008, pp. 75-83. doi:10.1016/S0304-8853(01)00465-6 